\title{
SARS-CoV-2 infection in general practice in Ireland: a seroprevalence study
}

\begin{abstract}
Michael E O'Callaghan ${ }^{1 *}$, Elizabeth Ryan ${ }^{2,3}$, Cathal Walsh ${ }^{3,4}$, Peter Hayes ${ }^{1,3}$, Monica Casey ${ }^{1,3}$, Pat O'Dwyer ${ }^{1}$, Aidan Culhane ${ }^{1}$, John W Duncan ${ }^{1}$, Pat Harrold ${ }^{1}$, Jarlath Healy ${ }^{1}$, Emmet Kerin ${ }^{1}$, Eimear Kelly ${ }^{1}$, Conor Hanrahann ${ }^{1}$, Ger P Lane ${ }^{1}$, Bernie Lynch ${ }^{1}$, Paraic Meaney ${ }^{1}$, Billy O'Connell ${ }^{1}$, Jim Galvin ${ }^{1}$, Norelee Kennedy ${ }^{3,5}$, Paul Burke ${ }^{1,6}$, Nuala H O'Connell ${ }^{1,6}$, Colum P Dunne ${ }^{1}$, Liam G Glynn ${ }^{1,3,7}$
\end{abstract}

${ }^{1}$ School of Medicine, University of Limerick, Limerick, Ireland; ${ }^{2}$ Department of Biological Sciences, University of Limerick, Limerick, Ireland; ${ }^{3}$ Health Research Institute, University of Limerick, Limerick, Ireland; ${ }^{4}$ Department of Mathematics and Statistics, University of Limerick, Limerick, Ireland; ${ }^{5}$ School of Allied Health, University of Limerick, Limerick, Ireland; ' ${ }^{6}$ niversity Hospital Limerick, Limerick, Ireland; ${ }^{7}$ Health Research Board Primary Care Clinical Trials Network Ireland, Galway, Ireland
*For correspondence: mike. ocallaghan@ul.ie

Competing interest: The authors declare that no competing interests exist.

Received: 03 March 2021 Accepted: 18 March 2021

Published: 30 June 2021

(c)This article is Open Access: CC BY license (https://creativecommons.org/licenses/by/4.0/)

Author Keywords: general practice, point-of-care systems, COVID-19, SARS-CoV-2, seroepidemiologic studies, serologic tests

Copyright (C) 2021, The Authors; DOI:10.3399/BJGPO.2021.0038

\section{Abstract}

Background: Severe acute respiratory syndrome coronavirus 2 (SARS-CoV-2) antibody testing in community settings may help us better understand the immune response to this virus and, therefore, help guide public health efforts.

Aim: To conduct a seroprevalence study of immunoglobulin G (lgG) antibodies in Irish GP clinics.

Design \& setting: Participants were 172 staff and 799 patients from 15 general practices in the Midwest region of Ireland.

Method: This seroprevalence study utilised two manufacturers' point-of-care (POC) SARS-CoV-2 immunoglobulin M (IgM)_lgG combined antibody tests, which were offered to patients and staff in general practice from 15 June to 10 July 2020.

Results: IgG seroprevalence was $12.6 \%$ in patients attending general practice and $11.1 \%$ in staff working in general practice, with administrative staff having the lowest seroprevalence at $2.5 \%$ and nursing staff having the highest at $17.6 \%$. Previous symptoms suggestive of COVID-19 and history of a polymerase chain reaction (PCR) test were associated with higher seroprevalence. IgG antibodies were detected in approximately $80 \%$ of participants who had a previous PCR-confirmed infection. Average length of time between participants' positive PCR test and positive lgG antibody test was 83 days.

Conclusion: Patients and healthcare staff in general practice in Ireland had relatively high rates of IgG to SARS-CoV-2 compared with the national average between 15 June and 10 July 2020 (1.7\%). Fourfifths of participants with a history of confirmed COVID-19 disease still had detectable antibodies an average of 12 weeks post-infection. While not proof of immunity, SARS-CoV-2 POC testing can be used to estimate lgG seroprevalence in general practice settings.

\section{How this fits in}

The immune response to the SARS-CoV-2 virus continues to be characterised. This study examined for presence of lgG in 172 general practice staff and 799 patients from 15 June to 10 July 2020. While rates of seroprevalence were higher than estimated population-wide levels, they do not suggest COVID-19 has passed silently through our communities to any large degree. POC serologic studies 
can easily be integrated into routine general practice, and may help inform seroprevalence studies and other public health efforts required during this pandemic.

\section{Introduction}

A novel virus, SARS-CoV-2, first detected in Wuhan, China, in December 2019, ${ }^{1}$ caused a global pandemic and >3.7 million deaths worldwide by 8 June 2021. ${ }^{2}$ The rapid spread of SARS-CoV-2, asymptomatic infection, and the requirement to understand how vaccination will impact the pandemic have fuelled interest in large-scale screening. ${ }^{3-8}$

The standard method for diagnosis of SARS-CoV-2 infection remains a nucleic acid real-time PCR test. Although these tests have low levels of false positives, they are limited by a relatively high rate of false-negative results owing to multiple influencing factors, including virus shedding rates and the technical difficulty of performing an effective nasopharyngeal swab. ${ }^{9}$ While rapid, easily deployed, POC testing has been employed successfully in cohorting patients with viral illness, specifically influenza, ${ }^{10}$ POC antigen tests to detect active SARS-CoV-2 infection in real-world settings, while evolving, have yet to replace PCR testing. ${ }^{11,12}$

While unlikely to impact on acute management, use of reliable POC tests for antibodies as a result of infection or vaccination may provide additional relevant information to public health authorities in their management of the pandemic. 5 ,8 Many rapid, simple, POC lateral flow immunoassay (LFIA) tests to simultaneously detect IgM and IgG antibodies against SARS-CoV-2 in human blood within 15 minutes have been developed. ${ }^{13,14}$ Performance characteristics of these tests vary, although a majority have sensitivities of $>80 \%$ when used after day 15 of infection. ${ }^{15-17}$ If this lag between infection and detectable antibody levels ${ }^{17-19}$ is accounted for, POC antibody tests can help identify who has been previously infected. ${ }^{17,20}$ How long such antibodies will persist is unclear, although studies thus far have confirmed their presence for at least 6 months. ${ }^{21-24}$

Much is still unknown about the immune response to COVID-19, such as whether antibodies created in response to infection or vaccination confer protection from severe disease, from reinfection, or for how long protection might be sustained. ${ }^{23-28}$ Reinfections, potentially by genomically different virus strains, ${ }^{29,30}$ are also a source of concern, as are new variant strains with increased transmissibility. ${ }^{31}$

Natural active immunity from previous infection seems to prevent reinfection in approximately $80 \%$ of cases (although this figure is lower for older patients), ${ }^{29}$ but the role IgG antibodies play is not well defined. It appears upwards of $80 \%$ of those infected by SARS-CoV-2 make lgG antibodies in response ${ }^{25,26}$ and this group continues to make lgG antibodies for $>6$ months, ${ }^{23,27}$ which is a figure that is being revised upwards as time passes. Titres do drop over time but numbers of memory $B$ cells ${ }^{27}$ and the proportion of those with detectable antibodies seem to remain stable. ${ }^{23}$ However, the immune response is complex, involving memory B cells, antibodies, memory CD4+ T cells, and/or memory CD8+ T cells. Thus, it seems simple serological tests for SARS-CoV-2 antibodies may never adequately describe the 'richness and durability' of immune memory to COVID-19. ${ }^{24}$ Nevertheless, at population level, these tests may assist seroprevalence studies and assessment of those with longterm clinical sequelae. ${ }^{28}$

Therefore, well-designed studies, with clear reporting of time lag between diagnosed infections and antibody detection, ${ }^{17}$ to elucidate the mechanisms and serological correlates of protective immunity, may help guide rational clinical and public health policies.

As there is limited published information on the deployment of antibody POC tests in primary care settings, and none, to the authors' knowledge, in the Irish population, the aim was to conduct a seroprevalence study among patients and healthcare workers in general practice in Ireland for SARSCoV-2 using combined lgM-lgG antibody POC tests.

\section{Method}

General practices of the University of Limerick Education and Research Network for General Practice (ULEARN-GP) ${ }^{32}$ were invited to participate by email and follow-up phone call. This network comprises 134 practices in Ireland, centred around the Midwest. Acquisition of 1000 POC testing kits from two manufacturers determined the number of practices that could be approached as it was intended to offer kits to practices in batches of 25-50. A selection of small and large practices from villages, towns, and cities in the Midwest were emailed an invitation to participate in the study. If an invited practice 
Table 1 Characteristics of participating practices

\begin{tabular}{|c|c|c|c|c|c|}
\hline $\begin{array}{l}\text { Practice } \\
\text { code }\end{array}$ & $\begin{array}{l}\text { Practice location (vil- } \\
\text { lage, town, or city) }\end{array}$ & $\begin{array}{l}\text { Practice size (small, } \\
\text { medium, or large) }\end{array}$ & $\begin{array}{c}\text { Geographic spread (Clare, } \\
\text { Limerick, or Tipperary) }\end{array}$ & $\begin{array}{c}\text { Completed POC } \\
\text { tests, } n\end{array}$ & $\begin{array}{c}\text { Positive POC tests, either } \\
\text { type positive, } \mathbf{n}(\%)\end{array}$ \\
\hline 1 & Village & Small & Clare & 97 & $6(6)$ \\
\hline 2 & Town & Medium & Clare & 29 & $3(10)$ \\
\hline 3 & Town & Medium & Clare & 49 & $4(8)$ \\
\hline 4 & Village & Small & Clare & 50 & $0(0)$ \\
\hline 5 & Town & Large & Clare & 52 & $1(2)$ \\
\hline 6 & Village & Small & Clare & 50 & $6(12)$ \\
\hline 7 & Town & Medium & Limerick & 322 & $74(23)$ \\
\hline 8 & Village & Small & Limerick & 50 & $1(2)$ \\
\hline 9 & Village & Small & Limerick & 17 & $2(12)$ \\
\hline 10 & City & Large & Limerick & 50 & $4(8)$ \\
\hline 11 & City & Large & Limerick & 50 & $2(4)$ \\
\hline 12 & City & Large & Limerick & 50 & $2(4)$ \\
\hline 13 & Village & Medium & Limerick & 45 & $10(22)$ \\
\hline 14 & Town & Medium & Tipperary & 27 & $2(7)$ \\
\hline 15 & Town & Small & Tipperary & 33 & $1(3)$ \\
\hline
\end{tabular}

avillage (population <1500), town (population 1500-10 000), and city (population >10 000). bSmall (General Medical Services [GMS] list <1000), medium (GMS list 1000-2000), and large (GMS list >2000).

declined to participate, the next similar practice in the network was chosen until all POC tests were distributed. Details of participating practices are shown in Table 1.

Participants needed to be aged $\geq 18$ years and able to provide consent, and be either staff or a patient at one of the general practice sites. Exclusion criteria were: cognitive impairment; severe psychiatric illness; use of immunologic agents; or pregnancy. There were no incentives provided to these practices to participate, although personal protective equipment (PPE) was supplied along with the equipment required to perform the study.

Two different serological POC kits for qualitative analysis of IgG and IgM directed against the receptor-binding domain of the SARS-CoV-2 spike protein were used: SARS-CoV-2 IgM/lgG Antibody Assay Colloidal Gold Complex test (Maccura Biotechnology Ltd, Chengdu, China) and the 2019nCoV IgG/IgM Antibody Rapid test (Diagreat Biotechnologies Co Ltd, Beijing, China) with reported sensitivity and specificity for $\operatorname{lgG}$ of $71 \%$ and $98 \%,{ }^{13}$ and $83 \%$ and $93 \%,{ }^{33}$ respectively. All testing was performed in GP settings over a 4-week period from 15 June to 10 July 2020, in accordance with the manufacturers' directions. Of note, this study is not intended as an assessment of the diagnostic performance of the lateral flow assays used (see Supplementary Table S1).

For the study period, all patients attending participating practices for routine care were informed about the study taking place and that they could participate if they so wished. Patients were informed that they would be blinded to the results of their POC test. Interested patients were provided with an information leaflet, and allowed time to consider whether or not they wanted to participate. Those who consented to participate then chose whether to supply a pinprick capillary blood sample or a single ethylenediaminetetraacetic acid (EDTA) blood sample via venepuncture; several drops of blood were applied to a small test cartridge along with a buffer solution for each of two separate test kits, and results read 15 minutes later.

Finally, a brief clinical history was taken (see Supplementary Box S1) and recorded on a standardised data collection sheet in order to estimate onset of relevant symptoms since the beginning of the pandemic, if any, and previous PCR testing for SARS-CoV-2 via nasopharyngeal swab. Evidence of previous PCR results were obtained directly from patient testimony, although in practice, owing to the involvement of GPs in referral for community-based testing, many tests could be verified on the practice electronic medical record. 
For quality assurance, 20 randomly selected samples from a bank of previously collected serum samples (10 samples from 2007 to 2008 and 10 samples from 2017 to 2018) were also tested with both kits as part of this study. All 20 samples were found to be negative, and the test control markers reacted appropriately and as specified.

Seroprevalence was defined as the proportion of participants who had a positive result for the IgG band on the two test kits used in the study. As in similar studies internationally, owing to the differences in sensitivity and specificity of the lgM antibody, its shorter duration, and the heterogeneity of IgM results seen previously, ${ }^{18,19,34}$ seroprevalence results presented herein are based only on IgG antibodies.

In order to convert the observed positive and negative values of each test to a population level estimate of seroprevalence, the reported data on sensitivity and specificity were used for each test. ${ }^{13,33}$ Of note, the probability an individual tests positive on a given test is the probability that they have true disease multiplied by the sensitivity of the test plus the probability that they do not have true disease multiplied by 1 - specificity of the test. Inverting this relationship allows estimation of true seroprevalence given the test results.

Since the estimated sensitivity and specificity of the tests are based on relatively small numbers, ${ }^{13,33}$ this process was carried out using Monte Carlo estimation and $95 \%$ confidence intervals (Cls) are reported. The Strengthening the Reporting of Observational Studies in Epidemiology (STROBE) checklist ${ }^{35}$ was followed during design of this study. Analyses were completed using R (version 4.0.5) and IBM SPSS Statistics (version 24.0).

\section{Results}

\section{Practice recruitment}

Fifteen practices were approached to participate in the study and all agreed to do so, with allocation of POC tests varying according to practice size and scope of practices to recruit during the 4-week study period (Table 1).

\section{Participant recruitment and characteristics}

From these practices, 971 participants ( $n=799$ patients, $n=172$ staff) were recruited and tested using both POC test kits (Table 2). Venepuncture was favoured by 910 participants. The number of participants drawn from each practice was determined by the size of the practice and whatever was feasible for the practice to recruit in the 4 weeks of the study. The mean age of participants was 53.0 years (standard deviation [SD] 17.2) with an age range of 18-97 years. Of the entire cohort, $60 \%$ were female, $82 \%$ were patients, and the remainder (18\%) were healthcare staff with similar numbers of administration staff, nursing staff, doctors, and other healthcare staff across this group. With regard to previous testing, 139 (14\%) had undergone prior PCR testing for SARS-CoV-2 and 33 of these (24\%) had tested positive.

Regarding previous symptoms suggestive of SARS-CoV-2, 339 (35\%) of all participants described such symptoms, of which the majority (57\%) were 'moderate' in severity. Less than one-third (32\%) of those patients with previous relevant symptoms had undergone a PCR test for SARS-CoV-2, and 17\% of those who were seropositive were asymptomatic in the months preceding the testing.

\section{Seroprevalence}

Of the 971 participants, 967 had valid test results using the Maccura test kit and 918 using the Diagreat test kits, with 914 participants having valid test results for both test kits (see Table 3 for full results for both kits). One practice only used a single test kit (Maccura) instead of both on all participants resulting in reduced numbers for the Diagreat test. A control strip did not appear for a single participant for each test kit (99.9\% performance for the control strip for each test kit) so both of these results were excluded from the final analysis.

Seroprevalence was estimated with greater precision by the Maccura test owing to the greater amount of performance data available ${ }^{13}$ on its sensitivity and specificity. Seroprevalence based on the Maccura test was estimated to be $12.6 \%(95 \% \mathrm{Cl}=7.5 \%$ to $16.6 \%)$ in patients attending general practice and $11.1 \%(95 \% \mathrm{Cl}=4.2 \%$ to $18.6 \%)$ in staff working in general practice. Administrative staff exhibited lowest seroprevalence at $2.5 \%(95 \% \mathrm{Cl}=0.0 \%$ to $16.7 \%)$ and nursing staff the highest at 
Table 2 Baseline characteristics of all participants, including previous symptoms, PCR testing, and antibody detection

\begin{tabular}{|c|c|c|c|c|c|c|c|c|}
\hline \multirow{2}{*}{$\begin{array}{l}\text { Participant charac- } \\
\text { teristics } \\
\text { Age, years }\end{array}$} & \multicolumn{2}{|c|}{ Total, $n=971$} & \multicolumn{2}{|c|}{$\begin{array}{l}\text { Previous symptoms sug- } \\
\text { gestive of SARS-CoV-2, } \\
\qquad n=339\end{array}$} & \multicolumn{2}{|c|}{$\begin{array}{l}\text { Previous PCR naso- } \\
\text { pharyngeal swab for } \\
\text { SARS-CoV-2, } \\
n=139\end{array}$} & \multicolumn{2}{|c|}{$\begin{array}{c}\text { Either antibody test } \\
\text { positive, } \\
n=118\end{array}$} \\
\hline & Mean & SD & Mean & SD & Mean & SD & Mean & SD \\
\hline & 53.0 & 17.2 & 49.8 & 15.4 & 51.7 & 13.6 & 50.3 & 15.8 \\
\hline & Median & Range & Median & Range & Median & Range & Median & Range \\
\hline & 55 & $18-97$ & 51 & $18-88$ & 53 & $20-84$ & 54 & $18-80$ \\
\hline Sex & Patients, $n$ & Patients, \% & Patients, $n$ & Patients, \% & Patients, $n$ & Patients, \% & Patients, $n$ & Patients, \% \\
\hline Male & 392 & 40 & 120 & 35 & 50 & 36 & 46 & 39 \\
\hline Female & 579 & 60 & 219 & 65 & 89 & 64 & 72 & 61 \\
\hline \multicolumn{9}{|l|}{ Participant type } \\
\hline 1. Patient & 799 & 82 & 271 & 80 & 93 & 67 & 98 & 83 \\
\hline 2. Healthcare staff & 172 & 18 & 68 & 20 & 46 & 33 & 20 & 17 \\
\hline 2.1 Administration & 34 & 4 & 10 & 3 & 6 & 4 & 2 & 2 \\
\hline 2.2 Nursing & 51 & 5 & 24 & 7 & 16 & 12 & 8 & 7 \\
\hline 2.3 Doctor & 40 & 4 & 14 & 4 & 14 & 10 & 4 & 3 \\
\hline $\begin{array}{l}2.4 \text { Other } \\
\text { healthcare staff }\end{array}$ & 47 & 5 & 20 & 6 & 10 & 7 & 6 & 5 \\
\hline \multicolumn{9}{|l|}{$\begin{array}{l}\text { History PCR and } \\
\text { symptoms }\end{array}$} \\
\hline $\begin{array}{l}\text { Previous PCR test } \\
\text { for SARS-CoV-2 }\end{array}$ & 139 & 14 & 108 & 32 & 139 & 100 & 43 & 36 \\
\hline Positive PCR test & 33 & 24 & 28 & 26 & 33 & 24 & 27 & 63 \\
\hline $\begin{array}{l}\text { Previous symptoms } \\
\text { suggestive of SARS- } \\
\text { CoV-2 }\end{array}$ & 339 & 35 & - & - & 108 & 78 & 83 & 70 \\
\hline \multicolumn{9}{|l|}{$\begin{array}{l}\text { Severity of } \\
\text { symptoms }\end{array}$} \\
\hline Mild & 112 & 12 & 112 & 33 & 22 & 16 & 23 & 19 \\
\hline Moderate & 193 & 20 & 193 & 57 & 70 & 50 & 52 & 44 \\
\hline Severe & 34 & 4 & 34 & 10 & 16 & 12 & 8 & 7 \\
\hline
\end{tabular}

$\mathrm{PCR}=$ polymerase chain reaction. $\mathrm{SD}=$ standard deviation.

$17.6 \%(95 \% \mathrm{Cl}=5.9 \%$ to $33.8 \%)$. Seroprevalence was similar in males and females; was lowest in those aged $\geq 65$ years; and increased in those who had previous symptoms suggestive of SARS-CoV-2 or who had undergone a PCR test for SARS-CoV-2.

Of the 339 (35\%) participants who reported symptoms since the beginning of the pandemic, 83 (24\% of those reporting symptoms) demonstrated evidence of IgG to SARS-CoV-2.

For the 33 patients with previous PCR-confirmed COVID-19 infection, 27 (82\% of previously infected individuals) showed serologic evidence of IgG to SARS-CoV-2 with one or both of the kits. For this subgroup, mean duration between their positive PCR test and the positive serology test for IgG was 83 days $(95 \% \mathrm{Cl}=77$ to 89$)$. Of note, 28 of the 33 PCR-positive patients reported symptoms of COVID-19 before previously testing positive for COVID-19, whereas the remaining five were asymptomatic prior to their positive PCR test..

For the six previously diagnosed patients who did not show evidence of IgG on either test kit, mean duration between their positive PCR test and the serology test was 77 days $(95 \% \mathrm{Cl}=44$ to 111). Five of these patients reported symptoms of COVID-19 before their positive PCR test. 


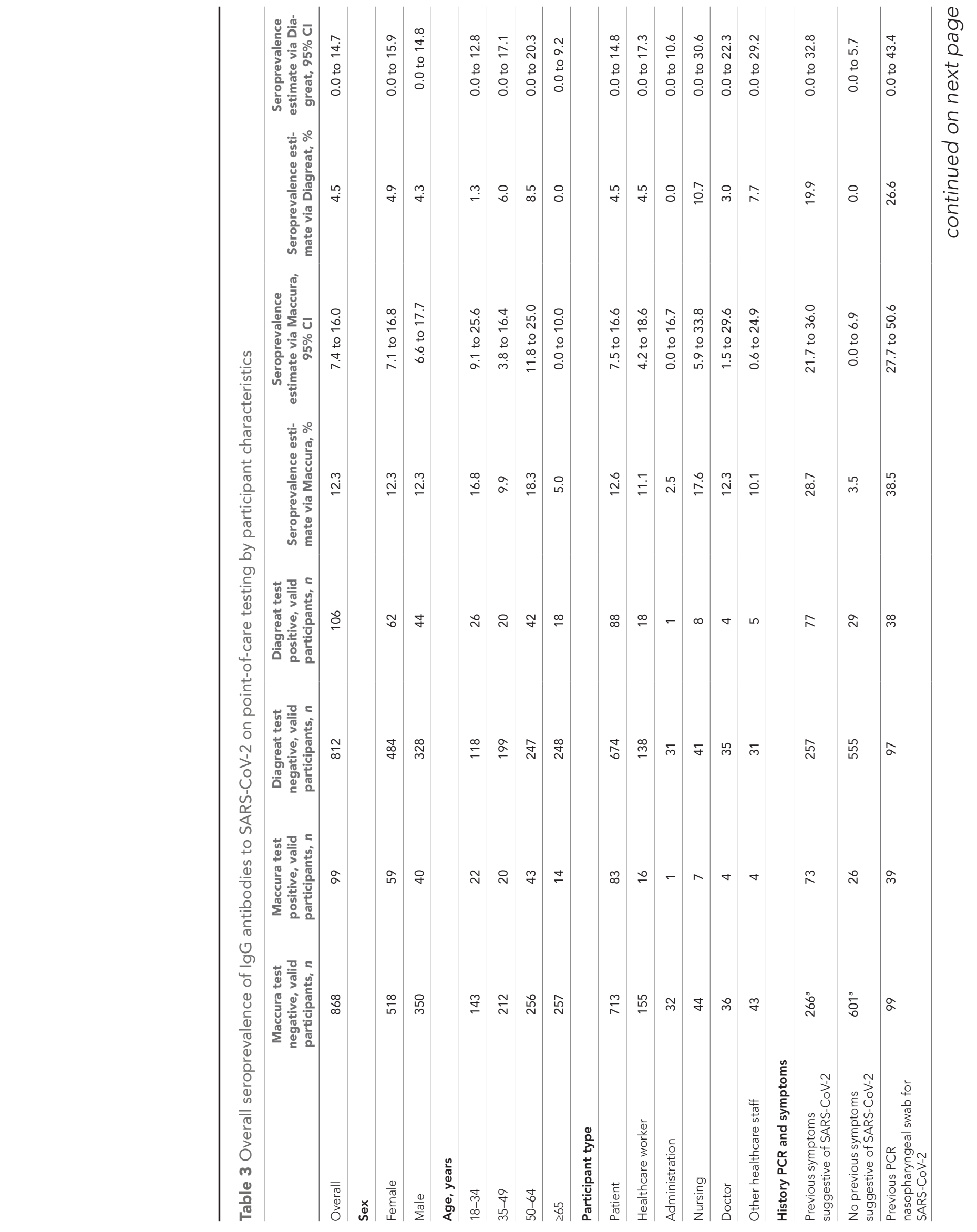




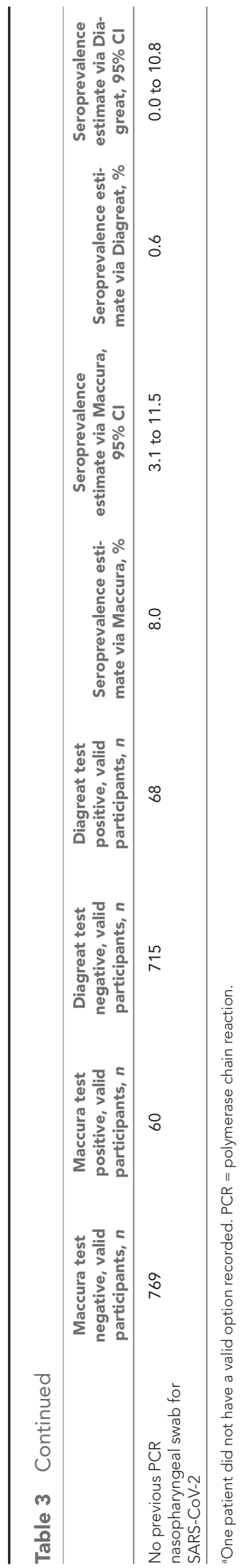


Table 4 Relationship between Diagreat and Maccura lgG test results and previously positive PCR tests for SARS-CoV-2

\begin{tabular}{lccc}
\hline & $\begin{array}{c}\text { IgG } \\
\text { negative, } \boldsymbol{n}\end{array}$ & $\begin{array}{c}\text { IgG } \\
\text { positive, } \boldsymbol{n}\end{array}$ & Total, $\boldsymbol{n}$ \\
\hline Diagreat Test & & & \\
\hline PCR negative & 89 & 13 & 102 \\
\hline PCR positive & 7 & 25 & 32 \\
\hline Total & 96 & 38 & 134 \\
\hline Maccura Test & & & \\
\hline PCR negative & 92 & 13 & 105 \\
\hline PCR positive & 7 & 26 & 33 \\
\hline Total & 99 & 39 & 138 \\
\hline
\end{tabular}

IgG = immunoglobulin $\mathrm{G}$. IgM = immunoglobulin $\mathrm{M}$. $P C R=$ polymerase chain reaction.

\section{Relative performance of $\mathrm{POC}$ tests with PCR testing}

Of the participants who had a valid Maccura test, 33 had previously tested positive on PCR for SARS-CoV-2 and 26 tested positive for lgG, demonstrating $79 \%(95 \% \mathrm{Cl}=64 \%$ to $94 \%)$ positivity. For the Diagreat test, 32 had previously tested positive on PCR for SARS-CoV-2 and 25 tested positive for IgG on the Diagreat test, demonstrating $78 \%(95 \% \mathrm{Cl}=63 \%$ to $93 \%)$ positivity (Table 4).

\section{Discussion}

\section{Summary}

Seroprevalence for SARS-CoV-2 lgG antibodies was $12.6 \%$ for patients attending general practice and $11.1 \%$ for practice staff. Nursing staff demonstrated the highest seroprevalence levels while administrative staff, presumably owing to relatively less direct patient contact, had lowest seroprevalence. Seroprevalence was similar across sex, was lowest in those aged $\geq 65$ years, and was increased in those who had previous symptoms suggestive of COVID-19 or who had undergone a PCR test for COVID-19.

Notably, more than two-thirds of participants with previous symptoms suggestive of COVID-19 had not undergone a PCR test for COVID-19. This likely reflects the fact that there was limited availability of PCR tests, and thus more stringent criteria for testing in Ireland in the early stages of the pandemic. ${ }^{36}$

Results across practices varied from no detection to lgG detection in $23 \%$ of participants, presumably owing to considerable variability in COVID-19 geographic spread early in the pandemic. The vast majority of participants chose venepuncture to provide the blood sample for analysis, presumably owing to the fact that obtaining several drops of blood by capillary blood sampling would be more painful. Additionally, many of these patients were likely to be attending general practice that day for phlebotomy, and participation in the study did not mean any additional venepuncture.

While recognising not all those with PCR-confirmed COVID-19 infection will have produced lgG in response ${ }^{25,26}$ and $\mathrm{lgG}$ levels can wane, ${ }^{27} \mathrm{lgG}$ antibodies were detected in $82 \%$ of participants with a confirmed prior COVID-19 infection, with a mean duration of nearly 3 months between diagnosis of infection and antibody detection.

\section{Strengths and limitations}

Key strengths of this study were the large number of patients from a reasonably wide selection of practices, which were recruited to the study with good representation across age and sex. Limitations include restriction of the study to the Midwest of Ireland and limited numbers of healthcare staff, meaning seroprevalence rates of the various staff categories had wide $\mathrm{Cls}$. However, practices were purposefully selected to represent the entire region and different communities within the region, which is borne out by the differing seroprevalence rates recorded.

Patients and staff who had a history of COVID-19 infection or suggestive symptoms may have been more willing to participate in the study to assess their 'immunity' and thus further studies are needed to establish true prevalence of antibodies in GP staff and patients, and how this is changing over time.

An additional limitation arises from using a previous positive PCR result as a proxy for true SARSCoV-2 infection in the seroprevalence analyses, as PCR tests have their own fallibilities. Similarly, any POC testing kit has inherent limitations, and lgG levels to SARS-CoV-2 are also known to drop in some patients over time. ${ }^{23,27}$ However, even with these limitations, the analyses reveal plausible seroconversion rates that help describe the known previous clinical history of many people in the study. 
Finally, some individuals do not develop a detectable antibody response for a variety of reasons, such as T-cell immune response, and these prior infections will not be detected in a seroprevalence study. ${ }^{24,28,37,38}$

\section{Comparison with existing literature}

Healthcare workers have been at higher risk of COVID-19 infection than the general population owing to exposure to infected patients and crowded enclosed environments. ${ }^{39-41}$ They have been shown to be more than 10 times more likely to contract COVID-19 compared with the general public, ${ }^{31}$ and evidence suggests hospital staff without direct patient contact are also at higher risk of infection. ${ }^{32}$

From the patient perspective, those with chronic conditions spend more time in general practice and other healthcare settings as they often need closer monitoring and more frequent treatment. ${ }^{42}$ It is plausible that such patients with increased medical need continued to visit many healthcare settings during the pandemic, thereby increasing their risk of contracting COVID-19 within these high-risk environments.

At the same time as the study was carried out, a national seroprevalence study (SCOPI) ${ }^{43}$ was undertaken by the Irish Health Protection Surveillance Centre (HPSC). This involved cross-sectional sampling of people living in two areas in Ireland: one with a high incidence of confirmed COVID-19 cases (Dublin); and the other with a lower incidence of confirmed COVID-19 cases (Sligo). The findings of the study were then extrapolated to estimate an overall prevalence for Ireland of $1.7 \%,{ }^{43}$ giving the participants in the present study a rate of infection more than seven times the national average at the time.

More recently, a large study of 5700 healthcare workers in two hospitals situated in areas of high COVID-19 incidence (Dublin) and lower incidence (Galway) has shown prevalence of SARS-CoV-2 lgG antibodies in $15.0 \%$ and $4.1 \%$ of participants, respectively. ${ }^{44}$

To the authors' knowledge, there are no seroprevalence data from community healthcare settings in Ireland available, and indeed little internationally, but data are available from Spain where a seroprevalence rate of $5.5 \%-5.9 \%$ has been demonstrated. ${ }^{45,46}$ The present study makes a valuable contribution to the knowledge regarding potential levels of circulating SARS-CoV-2 in such settings in Ireland and the methodology may assist future similar studies in Irish general practice.

As studies with longer follow-up emerge, ${ }^{21-28}$ persistence of antibodies in a majority of infected individuals for a reasonable length of time may be welcome news for vaccination efforts and indeed for those patients who have overcome COVID-19 infection. However, what lgG levels mean for protection from subsequent infection remains to be seen.

\section{Implications for research and practice}

Patients and healthcare staff in general practice in Ireland demonstrated higher evidence of COVID-19 infection than seen in the general public nationally and similar to rates seen in hospital-based healthcare workers in areas of high-disease activity.

Venepuncture was chosen over capillary blood sampling by most participants and routine venepuncture for other reasons in general practice may provide opportunities for future seroprevalence studies.

The number of individuals with detectable levels of IgG, if taken as a proxy for some degree of immunity, while greater than the national average, was far below that of a reasonable populationlevel 'herd immunity' threshold. ${ }^{38}$ This implies COVID-19 has not swept silently through community settings, and highlights the importance of continued compliance with simple public health measures until vaccination efforts mature and more is learnt about their effect on this pandemic.

Comparison of positive PCR results and the POC test kits demonstrates how use of distinct testing methods on the same participants can offer some quality assurance and compensation for each test's inherent fallibilities and differing sensitivities. While POC tests used in the study may not be conclusive about immunity to any or all strains of SARS-CoV-2, it seems prudent to continue study of this important aspect of the immune system's response to this novel virus.

Funding

The testing kits and limited PPE supplies (surgical masks, disposable gowns, and gloves) were supplied gratis by Diagreat Biotechnologies Co Ltd and Maccura Biotechnology Ltd. The companies had no input into the design, data collection, analysis, or reporting of the study. 
Ethical approval

This study was approved by the University Hospital Limerick Research Ethics Committee on 12 June 2020 (reference number: 057/2020).

\section{Provenance}

Freely submitted; externally peer reviewed.

\section{Acknowledgements}

The authors would like to thank all participating patients and staff from all participating practices in the Midwest who kindly gave the time and expertise needed for the testing and collection of data for this study.

\section{References}

1. Wu F, Zhao S, Yu B, et al. A new coronavirus associated with human respiratory disease in China. Nature 2020; 579(7798): 265-269. DOI: https://doi.org/10.1038/s41586-020-2008-3

2. World Health Organization. Weekly epidemiological update on COVID-19 - 8 June 2021. 2021; https://www.who. int/publications/m/item/weekly-epidemiological-update-on-covid-19---8-june-2021 (accessed 11 Jun 2021).

3. Abbasi K. Covid-19: screening without scrutiny, spending taxpayers' billions. BMJ 2020; 371: m4487. DOI: https:// doi.org//10.1136/bmj.m4487

4. European Centre for Disease Prevention and Control. Population-wide testing of SARS-CoV-2: country experiences and potential approaches in the EU/EEA and the United Kingdom. 2020; https://www.ecdc.europa.eu/sites/default/ files/documents/covid-19-population-wide-testing-country-experiences.pdf (accessed 11 Jun 2021).

5. US Food and Drug Administration. Coronavirus (COVID-19) update: serological test validation and education efforts. 2020; https://www.fda.gov/news-events/press-announcements/coronavirus-covid-19-update-serologicaltest-validation-and-education-efforts (accessed 11 Jun 2021).

6. Nikolai LA, Meyer CG, Kremsner PG, Velavan TP. Asymptomatic SARS coronavirus 2 infection: invisible yet invincible. Int J Infect Dis 2020; 100: 112-116. DOI: https://doi.org/10.1016/j.ijid.2020.08.076

7. Sayampanathan AA, Heng CS, Pin PH, et al. Infectivity of asymptomatic versus symptomatic COVID-19. Lancet 2021; 397(10269): 93-94. DOI: https://doi.org/10.1016/S0140-6736(20)32651-9

8. Wells CR, Townsend JP, Pandey A, et al. Optimal COVID-19 quarantine and testing strategies. Nat Commun 2021; 12(1): 356. DOI: https://doi.org/10.1038/s41467-020-20742-8

9. Arevalo-Rodriguez I, Buitrago-Garcia D, Simancas-Racines D, et al. False-negative results of initial RT-PCR assays for COVID-19: a systematic review. PLoS One 2020; 15(12): e0242958. DOI: https://doi.org/10.1371/journal.pone. 0242958

10. Teoh TK, Powell J, Kelly J, et al. Outcomes of point-of-care testing for influenza in the emergency department of a tertiary referral hospital in Ireland. J Hosp Infect 2021; 110: 45-51. DOI: https://doi.org/10.1016/j.jhin.2021.01.004

11. Dinnes J, Deeks JJ, Adriano A, et al. Rapid, point-of-care antigen and molecular-based tests for diagnosis of SARSCoV-2 infection. Cochrane Database Syst Rev 2020; 8(8): CD013705. DOI: https://doi.org/10.1002/14651858. CD013705

12. European Centre for Disease Prevention and Control. Technical report: options for the use of rapid antigen tests for COVID-19 in the EU/EEA and the UK. 2020; https://www.ecdc.europa.eu/sites/default/files/documents/Optionsuse-of-rapid-antigen-tests-for-COVID-19.pdf (accessed 11 Jun 2021).

13. Li Z, Yi Y, Luo X, et al. Development and clinical application of a rapid IgM-lgG combined antibody test for SARSCoV-2 infection diagnosis. J Med Virol 2020; 92(9): 1518-1524. DOI: https://doi.org/10.1002/jmv.25727

14. Riccò M, Ferraro P, Gualerzi G, et al. Point-of-care diagnostic tests for detecting SARS-CoV-2 antibodies: a systematic review and meta-analysis of real-world data. J Clin Med 2020; 9(5): 1515. DOI: https://doi.org/10.3390/ jcm9051515

15. Whitman JD, Hiatt J, Mowery CT, et al. Evaluation of SARS-CoV-2 serology assays reveals a range of test performance. Nat Biotechnol 2020; 38(10): 1174-1183. DOI: https://doi.org/10.1038/s41587-020-0659-0

16. Prazuck T, Colin M, Giachè S, et al. Evaluation of performance of two SARS-CoV-2 rapid IgM-lgG combined antibody tests on capillary whole blood samples from the fingertip. PLoS One 2020; 15(9): e0237694. DOI: https:// doi.org/10.1371/journal.pone.0237694

17. Deeks JJ, Dinnes J, Takwoingi Y, et al. Antibody tests for identification of current and past infection with SARSCoV-2. Cochrane Database Syst Rev 2020; 6(6): CD013652. DOI: https://doi.org/10.1002/14651858.CD013652

18. Risch M, Weber M, Thiel S, et al. Temporal course of SARS-CoV-2 antibody positivity in patients with COVID-19 following the first clinical presentation. Biomed Res Int 2020; 2020: 9878453 DOI: https://doi.org/10.1155/2020/ 9878453

19. To KK-W, Tsang OT-Y, Leung W-S, et al. Temporal profiles of viral load in posterior oropharyngeal saliva samples and serum antibody responses during infection by SARS-CoV-2: an observational cohort study. Lancet Infect Dis 2020; 20(5): 565-574. DOI: https://doi.org/10.1016/S1473-3099(20)30196-1

20. Ravi N, Cortade DL, Ng E, Wang SX. Diagnostics for SARS-CoV-2 detection: a comprehensive review of the FDAEUA COVID-19 testing landscape. Biosens Bioelectron 2020; 165: 112454. DOI: https://doi.org/10.1016/j.bios. 2020.112454 
21. Wajnberg A, Amanat F, Firpo A, et al. Robust neutralizing antibodies to SARS-CoV-2 infection persist for months. Science 2020; 370(6521): 1227-1230. DOI: https://doi.org/10.1126/science.abd7728

22. Hall V, Foulkes $S$, Charlett $A$, et al. Do antibody positive healthcare workers have lower SARS-CoV-2 infection rates than antibody negative healthcare workers? Large multi-centre prospective cohort study (the SIREN study), England: June to November 2020. medRxiv 2021. DOI: https://doi.org//10.1101/2021.01.13.21249642

23. He Z, Ren L, Yang J, et al. Seroprevalence and humoral immune durability of anti-SARS-CoV-2 antibodies in Wuhan, China: a longitudinal, population-level, cross-sectional study. Lancet 2021; 397(10279): 1075-1084. DOI: https://doi.org/10.1016/S0140-6736(21)00238-5

24. Dan JM, Mateus J, Kato Y, et al. Immunological memory to SARS-CoV-2 assessed for up to 8 months after infection. Science 2021; 371(6529): eabf4063. DOI: https://doi.org/10.1126/science.abf4063

25. Zhao J, Yuan Q, Wang H, et al. Antibody responses to SARS-CoV-2 in patients with novel coronavirus disease 2019. Clin Infect Dis 2020; 71(16): 2027-2034. DOI: https://doi.org/10.1093/cid/ciaa344

26. Markewitz R, Torge A, Wandinger K-P, et al. Clinical correlates of anti-SARS-CoV-2 antibody profiles in Spanish COVID-19 patients from a high incidence region. Sci Rep 2021; 11(1): 4363. DOI: https://doi.org/10.1038/s41598021-83969-5

27. Gaebler C, Wang Z, Lorenzi JCC, et al. Evolution of antibody immunity to SARS-CoV-2. Nature 2021; 591(7851): 639-644. DOI: https://doi.org/10.1038/s41586-021-03207-w

28. West R, Kobokovich A, Connell N, Gronvall GK. COVID-19 antibody tests: a valuable public health tool with limited relevance to individuals. Trends Microbiol 2021; 29(3): 214-223. DOI: https://doi.org/10.1016/j.tim.2020.11.002

29. Hansen $\mathrm{CH}$, Michlmayr D, Gubbels SM, et al. Assessment of protection against reinfection with SARS-CoV-2 among 4 million PCR-tested individuals in Denmark in 2020: a population-level observational study. Lancet 2021; 397(10280): 1204-1212. DOI: https://doi.org/10.1016/S0140-6736(21)00575-4

30. Tillett RL, Sevinsky JR, Hartley PD, et al. Genomic evidence for reinfection with SARS-CoV-2: a case study. Lancet Infect Dis 2021; 21(1): 52-58. DOI: https://doi.org/10.1016/S1473-3099(20)30764-7

31. Centers for Disease Control and Prevention. About variants of the virus that causes COVID-19. 2021; https://www. cdc.gov/coronavirus/2019-ncov/transmission/variant.html (accessed 11 Jun 2021).

32. O'Regan A, Hayes $\mathrm{P}, \mathrm{O}$ 'Connor $\mathrm{R}$, et al. The University of Limerick education and research network for general practice (ULEARN-GP): practice characteristics and general practitioner perspectives. BMC Fam Pract 2020; 21(1): 25. DOI: https://doi.org/10.1186/s12875-020-1100-y

33. Spicuzza L, Montineri A, Manuele R, et al. Reliability and usefulness of a rapid IgM-lgG antibody test for the diagnosis of SARS-CoV-2 infection: a preliminary report. J Infect 2020; 81(2): e53-e54. DOI: https://doi.org/10. 1016/j.jinf.2020.04.022

34. Pollán M, Pérez-Gómez B, Pastor-Barriuso R, et al. Prevalence of SARS-CoV-2 in Spain (ENE-COVID): a nationwide, population-based seroepidemiological study. Lancet 2020; 396(10250): 535-544. DOI: https://doi.org/10.1016/ S0140-6736(20)31483-5

35. von Elm E, Altman DG, Egger M, et al. The Strengthening the Reporting of Observational Studies in Epidemiology (STROBE) Statement: guidelines for reporting observational studies. PLoS Med 2007; 4(10): e296. DOI: https://doi. org/10.1371/journal.pmed.0040296

36. Department of Health, Ireland. Statement from the National Public Health Emergency Team — Tuesday 19 May. 2020; https://www.gov.ie/en/press-release/41d42e-statement-from-the-national-public-health-emergency-teamtuesday-19-/ (accessed 11 Jun 2021).

37. Le Bert N, Tan AT, Kunasegaran K, et al. SARS-CoV-2-specific T cell immunity in cases of COVID-19 and SARS, and uninfected controls. Nature 2020; 584(7821): 457-462. DOI: https://doi.org/10.1038/s41586-020-2550-z

38. Fontanet A, Cauchemez S. COVID-19 herd immunity: where are we? Nat Rev Immunol 2020; 20(10): 583-584. DOI: https://doi.org/10.1038/s41577-020-00451-5

39. Galanis P, Vraka I, Fragkou D, et al. Seroprevalence of SARS-CoV-2 antibodies and associated factors in healthcare workers: a systematic review and meta-analysis. J Hosp Infect 2021; 108: 120-134. DOI: https://doi.org/10.1016/j. jhin.2020.11.008

40. Nguyen LH, Drew DA, Graham MS, et al. Risk of COVID-19 among front-line health-care workers and the general community: a prospective cohort study. Lancet Public Health 2020; 5(9): e475-e483. DOI: https://doi.org/10.1016/ S2468-2667(20)30164-X

41. Hunter BR, Dbeibo L, Weaver CS, et al. Seroprevalence of severe acute respiratory coronavirus virus 2 (SARSCoV-2) antibodies among healthcare workers with differing levels of coronavirus disease 2019 (COVID-19) patient exposure. Infect Control Hosp Epidemiol 2020; 41(12): 1441-1442. DOI: https://doi.org/10.1017/ice.2020.390

42. van Oostrom SH, Picavet HSJ, de Bruin SR, et al. Multimorbidity of chronic diseases and health care utilization in general practice. BMC Fam Pract 2014; 15: 61. DOI: https://doi.org/10.1186/1471-2296-15-61

43. Health Service Executive, Health Protection and Surveillance Centre, University College Dublin. Preliminary report of the results of the Study to Investigate COVID-19 Infection in People Living in Ireland (SCOPI): a national seroprevalence study, June-July 2020. 2020; https://www.hpsc.ie/a-z/respiratory/coronavirus/ novelcoronavirus/scopi/SCOPI\%20report\%20preliminary\%20results\%20final\%20version.pdf (accessed 11 Jun 2021).

44. Allen N, Ni Riain U, Conlon N, et al. Prevalence of antibodies to SARS-CoV-2 in Irish healthcare workers. Phase 1 October 2020. Interim report; https://www.hpsc.ie/a-z/respiratory/coronavirus/novelcoronavirus/research/precise/ PRECISE\%20Study\%20Phase\%201\%20Interim\%20Report\%20January\%202021.pdf (accessed 18 Jun 2021).

45. Montenegro P, Brotons C, Serrano J, et al. Community seroprevalence of COVID-19 in probable and possible cases at primary health care centres in Spain. Fam Pract 2021; 38(2): 154-159. DOI: https://doi.org/10.1093/fampra/ cmaa096 
46. Martín V, Fernández-Villa T, Lamuedra Gil de Gomez M, et al. Prevalence of SARS-CoV-2 infection in general practitioners and nurses in primary care and nursing homes in the healthcare area of León and associated factors. Semergen 2020; 46 Suppl 1:-35-39. DOI: https://doi.org/10.1016/j.semerg.2020.05.014 